\title{
On the Use of Low Terahertz Band for 5G Indoor Mobile Networks
}

\author{
Turker Yilmaz ${ }^{\mathrm{a}, *}$, Ozgur B. Akan ${ }^{\mathrm{a}}$ \\ ${ }^{a}$ Next-generation and Wireless Communications Laboratory (NWCL), Department of Electrical and Electronics Engineering, \\ Koc University, Istanbul, 34450, Turkey
}

\begin{abstract}
Mobile data traffic is constantly rising at huge growth rates. One evolving method to counter this expansion is operation frequency, and so bandwidth, increase, as formal standardization activities on 60 gigahertz industrial, scientific and medical radio band began in 2005. In line with this, this paper proposes the utilization of low terahertz $(\mathrm{THz})$ band for the next-generation of mobile and wireless communications systems. Following the introduction and an overview of the low- $\mathrm{THz}$ band propagation properties, representative indoor simulations comparing the current fourth generation and proposed high frequency fifth generation networks are presented. The results show that, while it is possible to form and maintain stable communication links at low- $\mathrm{THz}$ band, techniques to reduce signal attenuation should be researched within all related subjects.
\end{abstract}

Keywords: Future wireless communication, 5G mobile communication, terahertz communication, millimeter wave communication, terahertz waves, numerical simulation

\section{Introduction}

The speed of our lives, and so the demand for information, are unendingly increasing. The device that keeps us connected permanently, mobile phone, is at the forefront of this new situation, in line with the everincreasing flash memory storage sizes [1]. As of 2014, global mobile communication subscription number is 7 billion, corresponding to a penetration rate of $96 \%$, with developed and developing countries standing at $121 \%$ and $90 \%$, respectively [2]. Together with user amount, usage also steadily increases, as average traffic per smartphone rose by $45 \%$ to $819 \mathrm{MB}$ per month in 2014, and this figure is expected to continue growing with a compound annual growth rate (CAGR) of $60.1 \%$ for the following 5 years [3]. Furthermore, mobile connection speeds are also escalating, with global average network downstream speed for smartphones rising to $6097 \mathrm{~Kb} / \mathrm{s}$ in 2014, corresponding to a yearly increase of $53 \%$ and the forecasted CAGR up to 2019 is given at $11 \%$, rising the speed to $10.4 \mathrm{Mb} / \mathrm{s}$ by the end of the period [3].

While continuous increase in subscriber amount and average traffic per subscriber mandate for capacity improvement from the next-generation wireless communication systems, mobile connection speeds force increase in peak data rates. Furthermore, considering the global mobile data traffic forecasts and peak data rate leaps between mobile telecommunication generations, downlink peak data rate designation for fifth generation (5G) mobile technologies has to be on the order of $10 \mathrm{~Gb} / \mathrm{s}[4]$. Conventional ways of raising data rate, i.e., increasing operation bandwidth or spectral efficiency or decreasing signalling overhead, are collectively known. Among these alternatives, spectral efficiency improvement efforts have traditionally led the research in academia, resulting in advanced technology for the area. Consistent with the excessive amount of effort that currently needs to be put in to obtain even the modest gains in spectral efficiency, industry's response has been the already finalized wireless personal area network (WPAN) and wireless local area network (WLAN) standardization activities on 60 gigahertz $(\mathrm{GHz})$ industrial, scientific and medical (ISM) radio band [5][6][7], with $300 \mathrm{GHz}$ aimed next.

\footnotetext{
${ }^{*}$ Corresponding author. Tel.: +90212338 1757 .

Email addresses: turkeryilmaz@ku.edu.tr (Turker Yilmaz), akan@ku.edu.tr (Ozgur B. Akan)
} 
In light of the stated arguments, we propose the employment of the low end of the terahertz $(\mathrm{THz})$ band for $5 \mathrm{G}$ wireless communications. International Telecommunication Union (ITU) Radiocommunication Sector (ITU-R) has allocated frequencies up to $275 \mathrm{GHz}$ [8], leaving higher frequencies, including the $\mathrm{THz}$ band, which can be defined to be between 0.3 and $10 \mathrm{THz}$, available for any radio service. As plans to include the $60 \mathrm{GHz}$ ISM band to the operation frequencies of WPAN and WLAN devices are already in motion, with first such commonplace devices expected to be on the market by 2016, mobile phones will likely follow the example. In fact, comprehensive urban propagation measurements up to $73 \mathrm{GHz}$ are already complete [9]. However, while the $60 \mathrm{GHz}$ band offers at most $9 \mathrm{GHz}$ of continuous bandwidth, only the first two THz transmission windows that are below $400 \mathrm{GHz}$ provides multiples of that spectrum. Moreover, according to the IEEE 802.11ad channel model [10], transmission characteristics of the $60 \mathrm{GHz}$ band are significantly different from the legacy 2.4 and $5 \mathrm{GHz}$ bands, such as the multipath contributions are limited to second order reflections, at most. If the current wireless communications trends are strong enough to cause a shift from the highly established frequencies, communication techniques, network architectures and user equipment (UE) to include $60 \mathrm{GHz}$ implementation, we argue that, displaying similar electromagnetic (EM) wave propagation properties, low- $\mathrm{THz}$ band can also be used without causing substantial further difficulties for much improved network capacity and peak data rate benefits.

To support our claims, following a general description of the channel characteristics of the low- $\mathrm{THz}$ band given in Section 2, indoor coverage simulations to compare one of the transmission windows from the low- $\mathrm{THz}$ band, namely $350 \mathrm{GHz}$, with an operation frequency selected from the highest allocated frequency band for fourth generation $(4 \mathrm{G})$ systems, that is $3.4 \mathrm{GHz}$, and the first transmission channel of the $60 \mathrm{GHz}$ ISM band are presented. The test environment, which is explained thoroughly in Section 3 together with the simulations, is directly replicated from the related ITU-R evaluation guideline [11], and therefore this work is the first publication in literature that presents the performance of $\mathrm{THz}$ band communications within a standardized environment. Section 4 provides results together with their analysis and subsequently paper is concluded.

\section{The Low Terahertz Band}

As the frequency increases, not just signal generation but also signal propagation gets tougher. Fig.1 illustrates the atmospheric attenuation up to $1 \mathrm{THz}$ together with the dry air component, calculated for the standard ground-level atmospheric conditions [12] and as per the Recommendation ITU-R P.676-9 [13]. Additionally included in the figure are the attenuations due to rain for rain rates of 4, 16 and $50 \mathrm{~mm} / \mathrm{h}$, representing moderate, heavy and violent rain categories, respectively. Recommendation ITU-R P.838-3 [14] provides the procedure to compute the specific attenuation due to rain for frequencies up to $1 \mathrm{THz}$ and horizontal polarization is assumed for calculations. According to the recommendation, the general behaviour of rain attenuation between 1 and $1000 \mathrm{GHz}$ is an increasing function with a declining rate which reaches its maximum at around $100 \mathrm{GHz}$ and then flatlines.

The figure shows three main local maxima in the $\mathrm{THz}$ band up to $500 \mathrm{GHz}$, occurring at $325.178 \mathrm{GHz}$ with $39.071 \mathrm{~dB} / \mathrm{km}, 380.225 \mathrm{GHz}$ with $292.984 \mathrm{~dB} / \mathrm{km}$ and $448.013 \mathrm{GHz}$ with $346.816 \mathrm{~dB} / \mathrm{km}$. Some of the important points of the rain attenuation curves, which are global maximum, value at $1 \mathrm{THz}$ and the mean attenuation amount in between, are illustrated in Table 1.

To extend the discussion further, in Fig.2 the impacts of temperature and air pressure on the gaseous attenuation is investigated. The values given to temperature in Fig.2a are 248,288 , and $328^{\circ} \mathrm{K}$ and to air

Table 1: Rain attenuation results

\begin{tabular}{|c|c|c|c|c|c|c|c|c|c|}
\hline \multirow{2}{*}{ Quantity } & \multicolumn{3}{|c|}{$4 \mathrm{~mm} / \mathrm{h}$} & \multicolumn{3}{|c|}{$16 \mathrm{~mm} / \mathrm{h}$} & \multicolumn{3}{|c|}{$50 \mathrm{~mm} / \mathrm{h}$} \\
\hline & Max & & Mean & $\operatorname{Max}$ & & Mean & Max & & Mean \\
\hline Frequency $(f, \mathrm{GHz})$ & 207.46 & 1000 & & 179.8 & 1000 & & 148.67 & 1000 & \\
\hline Attenuation $(\gamma, \mathrm{dB} / \mathrm{km})$ & 3.968 & 3.348 & 3.611 & 9.626 & 8.126 & 8.679 & 20.075 & 16.843 & 17.88 \\
\hline
\end{tabular}




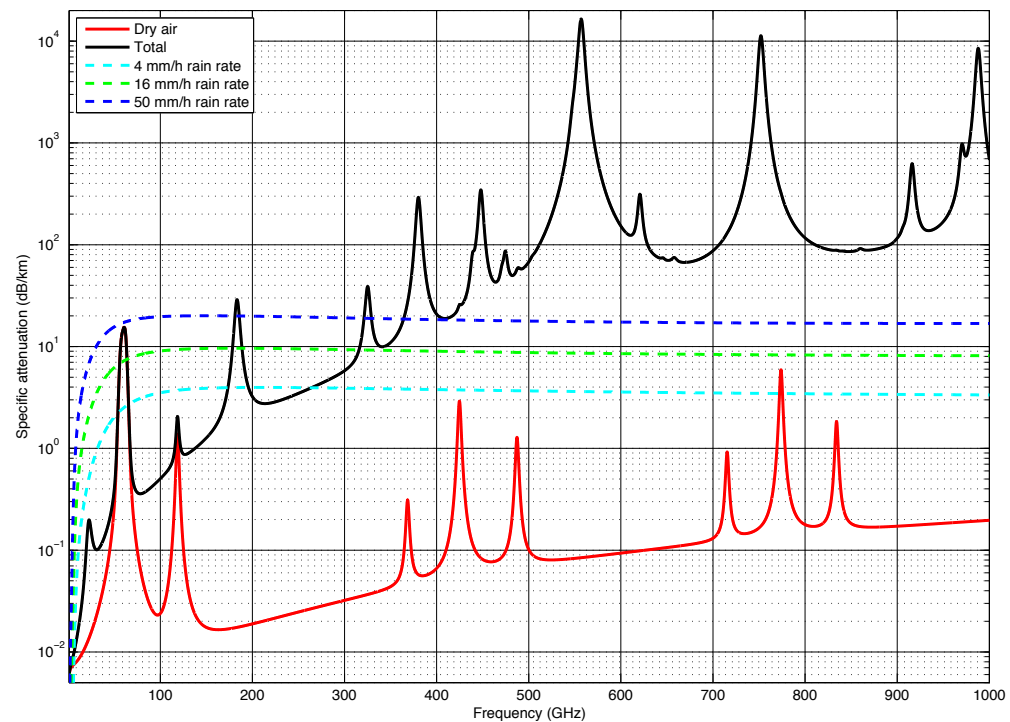

Figure 1: Specific attenuation due to atmospheric gases and rain, calculated up to $1 \mathrm{THz}$ at $1 \mathrm{MHz}$ intervals under standard ground-level atmospheric conditions and for rain rates of 4,16 and $50 \mathrm{~mm} / \mathrm{h}$.

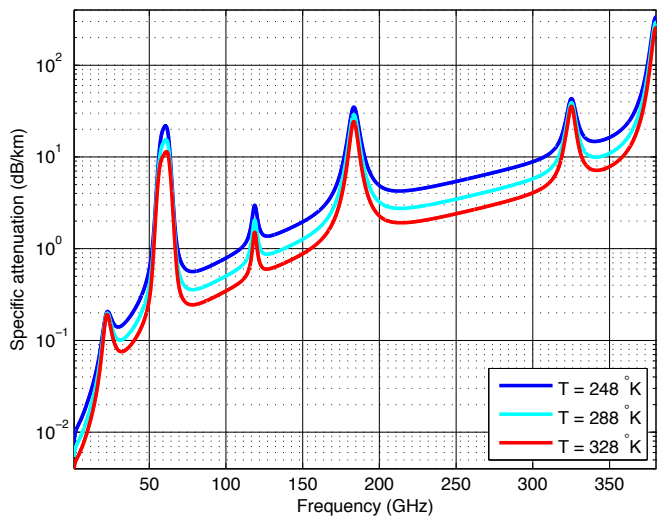

(a)

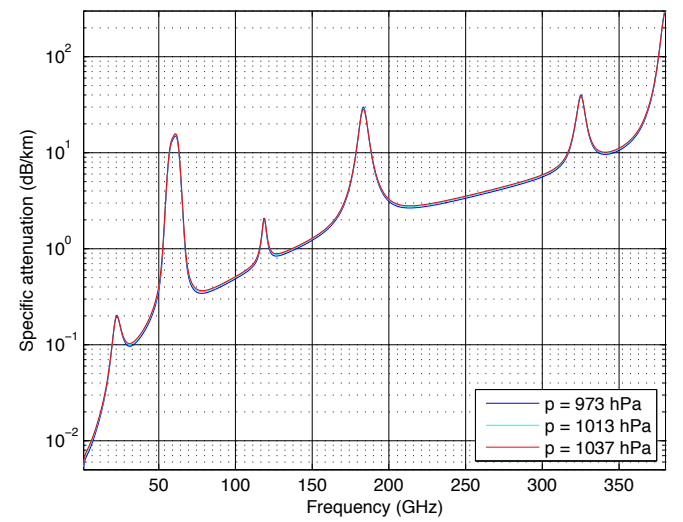

(b)

Figure 2: Specific attenuation due to atmospheric gases, calculated between $1 \mathrm{GHz}$ and $380.225 \mathrm{GHz}$ and for (a) temperatures of 248,288 , and $328^{\circ} \mathrm{K}$ and (b) pressures of 973,1013 and $1037 \mathrm{hPa}$.

pressure in Fig.2b are 973, 1013 and $1037 \mathrm{hPa}$. In the computations, the remaining two parameters are kept at standard atmospheric conditions.

The effect of water vapour density, as demonstrated in [15] and can also be construed from Fig.1, is supplementary to atmospheric attenuation; i.e. Attenuation rises with increasing water vapour density. According to Fig.2a, the opposite is true for temperature, whereas, while its impact is small compared to the other two factors, increasing air pressure also enhances gaseous attenuation.

While the detailed analysis of the attenuation components below the $\mathrm{THz}$ band is available in [16], in Fig. 3 emphasis is given on the specific attenuation between $275 \mathrm{GHz}$ and the third local maximum within the $\mathrm{THz}$ band at $448.013 \mathrm{GHz}$. The attenuation value at $275 \mathrm{GHz}$ is $4.362 \mathrm{~dB} / \mathrm{km}$ and the local minima among the first three $\mathrm{THz}$ band local maxima occur at $340.997 \mathrm{GHz}$ with $9.942 \mathrm{~dB} / \mathrm{km}$, and $409.017 \mathrm{GHz}$ with $18.871 \mathrm{~dB} / \mathrm{km}$. If we define transmission windows within the low- $\mathrm{THz}$ band as spectrum which has 


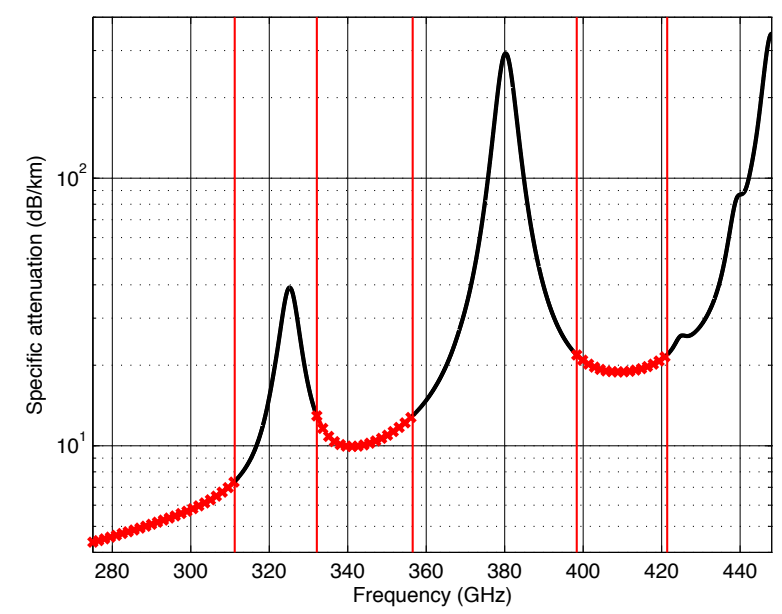

Figure 3: Specific attenuation due to atmospheric gases, calculated under ground-level atmospheric conditions and between $275 \mathrm{GHz}$ and $448.013 \mathrm{GHz}$ at $1 \mathrm{MHz}$ intervals, with $3 \mathrm{~dB}$ transmission windows around local minima indicated.

a maximum of $3 \mathrm{~dB} / \mathrm{km}$ attenuation difference with the local minimum it surrounds, the first three such bands above $275 \mathrm{GHz}$ emerge as detailed in Table 2 and marked within Fig.3.

A comparison of properties of the EM wave propagation in $300 \mathrm{GHz}$ with the 2.4, 5 and $60 \mathrm{GHz}$ bands indicates that the main difference is the additional free-space losses of $41.938,35.563$ and 13.979 $\mathrm{dB}$, respectively, for the same transmission distances [17]. At $300 \mathrm{GHz}$ attenuation by atmospheric gases is nearly $5.783 \mathrm{~dB} / \mathrm{km}$, whereas this attenuation is virtually non-existent for the 2.4 and $5 \mathrm{GHz}$ bands, and much higher for $60 \mathrm{GHz}$ at $15.037 \mathrm{~dB} / \mathrm{km}$. In-building material absorption is also greater at $300 \mathrm{GHz}$ [18]. Combining all these larger losses for $300 \mathrm{GHz}$ suggests that multipath would also be limited, at most, to first and second order reflections just like the IEEE 802.11ad's $60 \mathrm{GHz}$ channel models [10] and high-gain antennas will be necessary to maintain reliable communication links.

The upper frequency boundary for next-generation of mobile networks is certainly on the rise, with extensive field measurements for $28 \mathrm{GHz}, 38 \mathrm{GHz}$ and $73 \mathrm{GHz}$ are already performed [19][9], in addition to the theoretical research outputs [20][21]. However, to date, very little amount of study on channel measurement and propagation modelling at low-THz band has been conducted, as analogue [22] and digital [23][24] transmission demonstrations are recently performed and, to the best of the authors' knowledge, there is only one $\mathrm{THz}$ indoor channel model discussed in the literature [25]. The model was developed atop the previous works of the corresponding group and provides a stochastic solution for the frequency range between 275 and $325 \mathrm{GHz}$. All parameters for a complete channel transfer function, which are amplitude, polarization, time of arrival, phase, frequency dispersion and angles of arrival and departure, are claimed to be characterized. However, the model is far from final. Model parameter sets are based on one specific office scenario and, due to time constraints, outputs of ray tracing simulations are used instead of actual channel measurements. Reflected wave phase rotations are modelled to have a uniform distribution between $-180^{\circ}$ and $180^{\circ}$, thus including no particular information. Distributions of arrival and departure angles

Table 2: Probable transmission windows

\begin{tabular}{cccccc}
\hline \multicolumn{2}{c}{ Frequency Range } & & $\mathbf{f}_{\text {centre }}$ & Bandwidth \\
\hline 275 & - & 311.178 & $\mathrm{GHz}$ & 293.089 & 36.178 \\
332.094 & - & 356.532 & & 344.313 & 24.438 \\
398.338 & - & 421.377 & & 409.858 & 23.039 \\
\hline
\end{tabular}




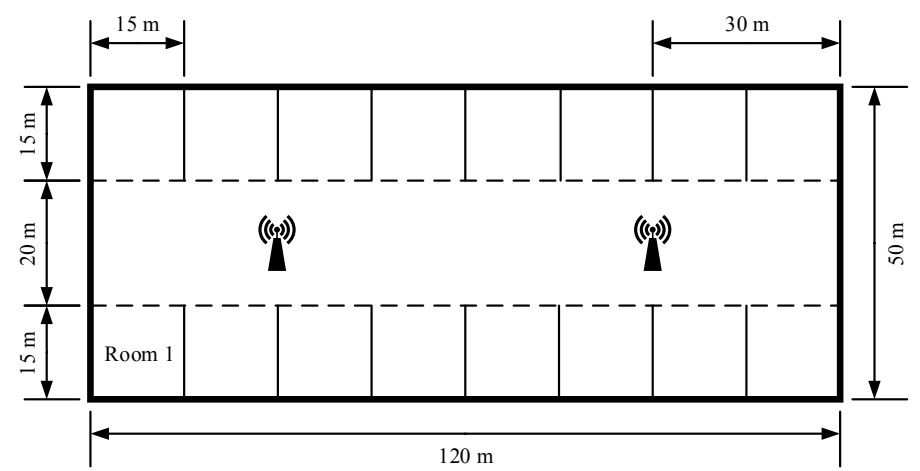

Figure 4: Sketch of the simulation environment with dimensions displayed.

are explored at length, however, those are the result of the geometry of the room and locations of the transmitters (TXs) and receivers $(\mathrm{RXs})$, rather than EM wave propagation. The usage of the model is also severely hindered because of the need to adapt the model with ray tracing for each new environment to be considered. Overall, despite its limitations, the channel model is another encouraging step towards a new wireless communication paradigm.

\section{Indoor Simulations}

Primary aim of the proposed millimetre wave (mm-wave) communication systems is increased peak data rates that are comparable to wired alternatives. Therefore, test environment in simulations is selected to maximize data rate and consequently, the indoor hotspot scenario of the indoor test environment from the four available scenarios identified in report ITU-R M.2135-1 [11] is chosen.

The scenario is set on one floor of a building having dimensions of 120 metres $(\mathrm{m}) \times 50 \mathrm{~m} \times 6 \mathrm{~m}$. There are eight rooms in both sides of the hall, having lengths and widths of $15 \mathrm{~m}$ each, leaving $20 \mathrm{~m}$ for the corridor. Two base stations (BSs) are installed to the ceiling of the floor, both in the middle and located $30 \mathrm{~m}$ away from the borders of the hall. All simulations are conducted over this plan, the sketch of which is available in Fig.4, and the missing information is supplied from the authors' laboratory building for the purpose of authenticity. The walls are therefore assumed to be $0.2 \mathrm{~m}$ thick and constructed of sand-lime brick (SLB).

A total of five simulations are performed, the first one for the $4 \mathrm{G}$ case, the next three on the $5 \mathrm{G}$ and the final one to compare the idealized $5 \mathrm{G}$ setting with the realistic $60 \mathrm{GHz}$ deployment in [26]. 4G

Table 3: Simulation parameters

\begin{tabular}{lccc}
\hline \multicolumn{1}{c}{ Quantity } & 4G & & 5G \\
\hline Transmitting power & 24 & $\mathrm{dBm}$ & 0 \\
TX and RX antenna gains & 0 & $\mathrm{dBi}$ & 23 \\
Carrier frequency & 3.4 & $\mathrm{GHz}$ & 350 \\
Noise bandwidth & 0.04 & & 10.8 \\
BS noise figure & 5 & $\mathrm{~dB}$ & 5 \\
UE noise figure & 7 & & 7 \\
System margin & 10 & & 5 \\
\hline
\end{tabular}


simulation parameters, except for the system margin (SM), are selected directly from the baseline evaluation configuration of the indoor hotspot scenario given in [11], and listed in Table 3. SM is assumed to be 10 $\mathrm{dB}$. Received power and signal-to-noise ratio (SNR) are calculated for every simulation, and for the $4 \mathrm{G}$ case, line-of-sight and non-line-of-sight (NLoS) path loss models from [11] are used for these purposes, as described in depth within our previous work [26].

Three different simulations are performed for $5 \mathrm{G}$ to thoroughly assess the transmission characteristics of mm-wave. While all $5 \mathrm{G}$ simulations are conducted on the same floor plan as in the $4 \mathrm{G}$ case, the first simulation additionally replicates the BS locations and building properties, such as the thickness and constituent of the walls, as well. In the second simulation, a more favourable environment for low- $\mathrm{THz}$ band propagation is assumed, with one BS located at the centre of the ceiling of each room, and the rooms are assumed to be separated from the corridor with a $0.02 \mathrm{~m}$ thick clear window glass, imitating a modern office setting. Moreover, the BSs in the hall are removed to test if non-stationary users can be supported by access points (APs) within the rooms. Finally, the third 5G simulation portrays a rather ideal situation, where BSs are available in every room and the hall. Additionally, hardware used is assumed to be superior, reflected by reducing each of the noise figures (NFs) and SM by $3 \mathrm{~dB}$ compared to other $5 \mathrm{G}$ simulations. The last 60 $\mathrm{GHz}$ simulation is also run on this setting, using the parameter and methods of [26] for comparison purposes.

Characterization of building materials in the $\mathrm{THz}$ range is available only from $350 \mathrm{GHz}$ and onwards in the literature [18]. Therefore, the second $\mathrm{THz}$ transmission window centred around $344.313 \mathrm{GHz}$ is chosen for $5 \mathrm{G}$ simulations, and $350 \mathrm{GHz}$ is considered as the corresponding centre frequency for the remaining of the paper. Standardization activities for the $60 \mathrm{GHz}$ ISM band were completed with channel spacing set at $2160 \mathrm{MHz}$. Taking a proportional approach, for the $5 \mathrm{G}$ simulations channel bandwidth is selected to be $10.8 \mathrm{GHz}$

The arguments behind the choices of $0 \mathrm{dBm}$ transmitted power and $23 \mathrm{dBi} \mathrm{TX}$ and $\mathrm{RX}$ antenna gains are presented at length in [15]. Moreover, like 4G simulation, the same NFs and ground-level atmospheric conditions are used for $5 \mathrm{G}$ calculations. The only difference for the SNR computation is the reduced SM of $5 \mathrm{~dB}$, which is selected due to the narrow half-power beamwidth caused by high antenna directivities.

Wide-ranging channel models are not present for $5 \mathrm{G}$ as in the $4 \mathrm{G}$ instance. Therefore, ray tracing method is employed [27]. Diffraction is shown to be insignificant in almost all propagation cases above 60 $\mathrm{GHz}$ [28]. Therefore, it is not included in the computations. The surfaces of the simulation environment are also assumed to be perfectly smooth, consistent with [25], thus nullifying diffuse scattering and making reflection the only mechanism to contribute to the NLoS coverage. The link budget based procedure is, again, explained fully in [15].

While reflection coefficients of a variety of materials tend not to alter noticeably in the low-THz band [29], absorption coefficients increase at different rates [18]. The two materials which are selected for simulations, SLB and glass, show further similarity in their absorption behaviour towards mm-waves. While absorption coefficients of SLB and glass are measured to be 171 and $195 \mathrm{~m}^{-1}$ at $100 \mathrm{GHz}$, and 909 and $995 \mathrm{~m}^{-1}$ at 350 $\mathrm{GHz}$, respectively, their absorption coefficient plots are also intertwined between 100 and approximately 400 $\mathrm{GHz}[18]$. 5G simulation parameters overall are also summarized in Table 3.

\section{Results and Discussion}

Simulation resolution is chosen as 1 centimetre $(\mathrm{cm}) \times 1 \mathrm{~cm} \times 1 \mathrm{~cm}$ within the defined floor of a building. The results are provided for a single height of $1 \mathrm{~m}$, selected to be between average heights of a desk and ear level of a standing person. Additionally, Table 4, within which TN denotes thermal noise, lists the received power and SNR extrema for the $4 \mathrm{G}$ and $5 \mathrm{G}$ simulations in both the corridor and room in the bottom left corner, which is indicated as Room 1 in Fig.4.

\section{1. $4 G$}

In Fig. 5 received power and SNR outcomes of the $4 \mathrm{G}$ simulation are presented. In all of the figures, the values within the walls and glass are set to the lowest outcome of the respective plane; therefore they are visible. The received power ranges from $0.763 \mu \mathrm{W}$, which points are directly below the BSs, to $0.195 \mathrm{nW}$, 


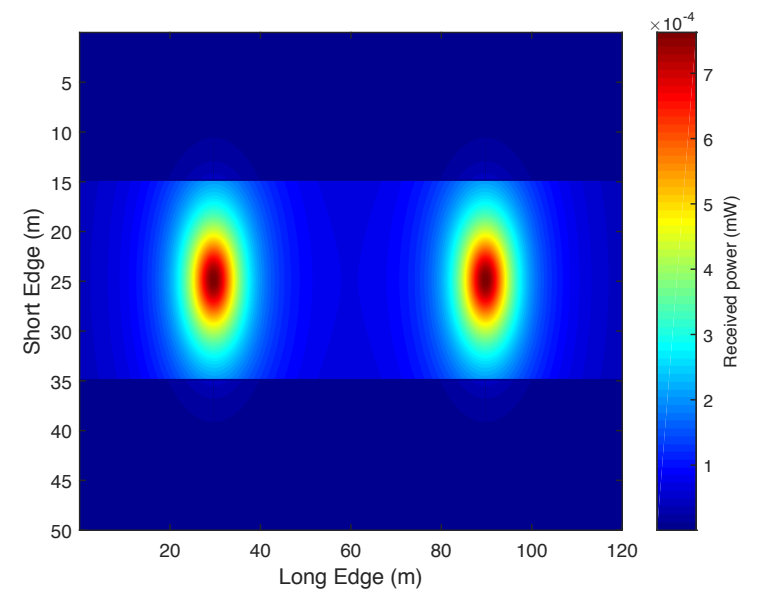

(a)

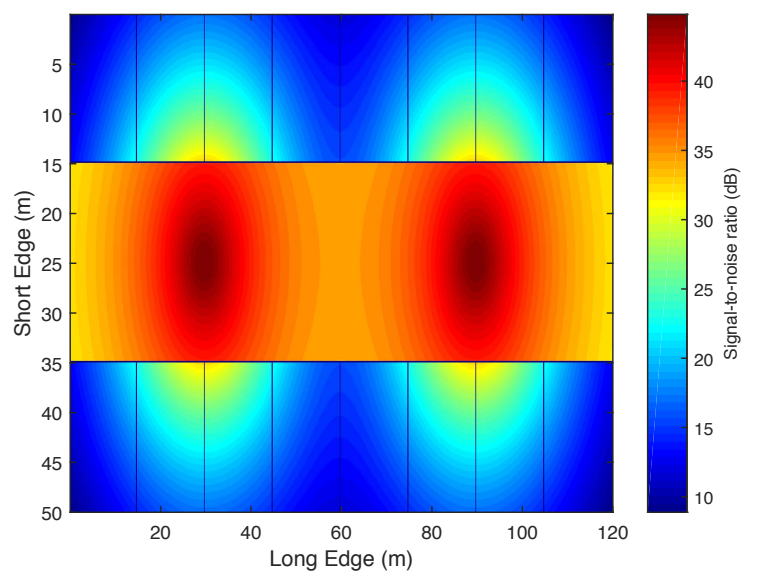

(b)

Figure 5: (a) Received power and (b) SNR performance of 4G indoor hotspot deployment simulation, displayed for $h=1$ m.

occurring at the corners of the floor, both as expected. Due to the proof of concept nature of the work, in all five simulations, total power at each modelled $1 \mathrm{~cm}^{3}$ volume is found by directly adding power received from all of the BSs. Consequently, $0.751 \mu \mathrm{W}$ of the maximum values is received from the BSs directly above the points, and $0.011 \mu \mathrm{W}$, or $1.47 \%$, is received from the distant BSs.

For practical purposes, SNR is more informative than the received power. Accordingly, the SNR outcome of the $4 \mathrm{G}$ simulation is available in Fig.5b. Since the BSs are located in the hall, values, which range from $31.81 \mathrm{~dB}$ to $44.81 \mathrm{~dB}$, are higher compared to the rooms. Maximum SNR received within the rooms is $32.31 \mathrm{~dB}$, which reduces down to the minimum of $8.89 \mathrm{~dB}$. For a bit error ratio (BER) of $10^{-6}$, successful transmission with 4-ary quadrature amplitude modulation (4-QAM), 16-QAM and 64-QAM require SNRs of $10.78,14.9$ and $19.42 \mathrm{~dB}$, respectively. While all these quantities are well below the results in the hall and most parts of the rooms, the lowest outcome of $8.89 \mathrm{~dB}$ forces BER of 4 -QAM reduce to $10^{-4}$ and $16-\mathrm{QAM}$ to $2 \times 10^{-2}$.

As the final statement of the subsection, for the points directly below the BSs, the total power of 0.763 $\mu \mathrm{W}$ those receive corresponds to $-31.18 \mathrm{dBm}$, whereas $0.751 \mu \mathrm{W}$ obtained solely from the closer BS is equal to $-31.24 \mathrm{dBm}$. The same values for the outermost points in the corridor are $-44.17 \mathrm{dBm}$ and $-44.86 \mathrm{dBm}$, respectively. These show that, at lengths over $60 \mathrm{~m}$, which is the distance between the two BSs positioned in hall, the assistance of the distant BS towards the SNR, and so to coverage, is notably negligible.

\section{2. $5 G$}

The first $5 \mathrm{G}$ simulation has the same deployment setting as in the $4 \mathrm{G}$ case, and the results are available in Fig.6. Firstly, when the scales of Fig.5a and Fig.6a are compared, a reduction on the order of $10^{2}$ is observed

Table 4: Simulation results

\begin{tabular}{|c|c|c|c|c|c|c|c|c|c|}
\hline \multirow{2}{*}{\multicolumn{2}{|c|}{ Quantity }} & \multicolumn{4}{|c|}{ Room 1} & \multicolumn{4}{|c|}{ Corridor } \\
\hline & & $4 \mathrm{G}$ & $5 \mathrm{G}$ & $5 \mathrm{G}_{\text {room }}$ & $5 \mathrm{G}_{\text {ideal }}$ & $4 \mathrm{G}$ & $5 \mathrm{G}$ & $5 \mathrm{G}_{\text {room }}$ & $5 \mathrm{G}_{\text {ideal }}$ \\
\hline \multirow{2}{*}{$\begin{array}{l}\text { Received } \\
\text { power }(\mu \mathrm{W})\end{array}$} & $\min$ & 0.0002 & $1.42 \times 10^{-253}$ & 0.0013 & 0.0013 & 0.0382 & 0.0002 & $5.38 \times 10^{-15}$ & 0.0002 \\
\hline & $\max$ & 0.0046 & $8.32 \times 10^{-98}$ & 0.0073 & 0.0073 & 0.7625 & 0.0073 & $4.16 \times 10^{-12}$ & 0.0073 \\
\hline \multirow{2}{*}{$S N R(\mathrm{~dB})$} & $\min$ & 8.8856 & $\ll \mathrm{TN}$ & -2.1454 & 6.8546 & 31.81 & -10.664 & -116.02 & -1.6714 \\
\hline & $\max$ & 22.652 & $\ll \mathrm{TN}$ & 5.3078 & 14.308 & 44.807 & 5.3337 & -87.138 & 14.334 \\
\hline
\end{tabular}




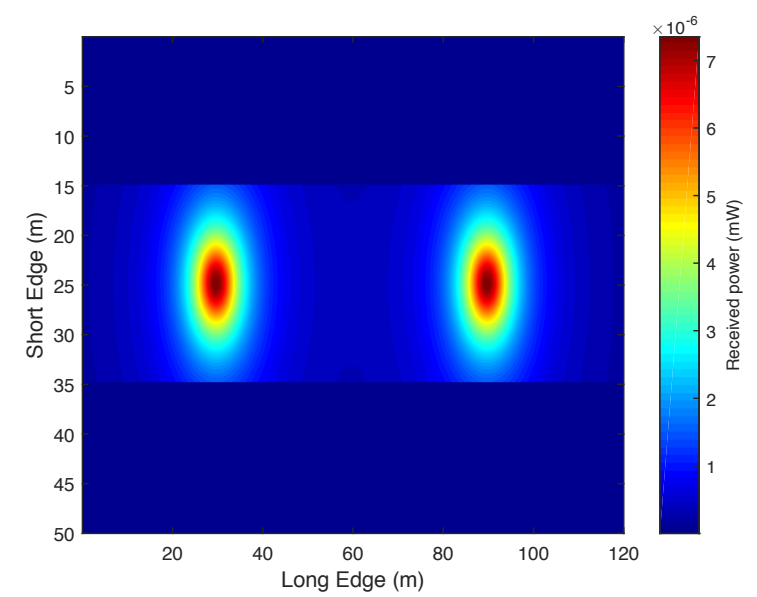

(a)

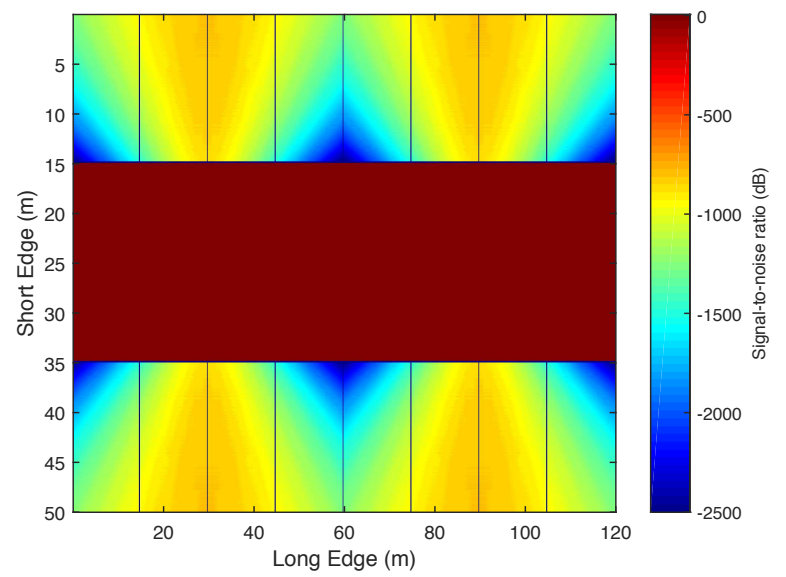

(b)

Figure 6: (a) Received power and (b) SNR performance of $5 \mathrm{G}$ mm-wave simulation for the indoor hotspot deployment setting, displayed for $h=1 \mathrm{~m}$.

for the $5 \mathrm{G}$ case, which translates into $20 \mathrm{~dB}$ of reduced signal power. Values in the corridor ranges from 7.35 $\mathrm{nW}$ to $0.1847 \mathrm{nW}$, whereas the corresponding values for the rooms are found to be between $1.27 \times 10^{-87} \mathrm{~mW}$ and $1.42 \times 10^{-256} \mathrm{~mW}$. While theoretically calculable, practically the latter values are unmeasurable. Thus, we can conclude that no signal penetration occurs through the $0.2 \mathrm{~m}$ thick SLB wall. In fact, according to Lambert-Beer's law, EM wave propagating through the stated barrier is attenuated by $789.54 \mathrm{~dB}$, therefore practically gets diminished. Furthermore, in reality, and thus reproduced exactly in our simulations, EM wave propagates through an even longer distance due to its angled incidence, and so the resulting oblique refraction path [30].

Fig.6b illustrates the SNR results of the first $5 \mathrm{G}$ simulation. The corridor values change between 5.33 $\mathrm{dB}$ and $-10.66 \mathrm{~dB}$, and range for the rooms is between $-812.3 \mathrm{~dB}$ and $-2501.79 \mathrm{~dB}$. Because the SNR values are below the noise floor, those values are not measurable in actuality. However, the colour scale of Fig.6b is still selected to cover all the values. This is both because for a scale between $5.33 \mathrm{~dB}$ and $-10.66 \mathrm{~dB}$, the resulting image looks very much like Fig.5a and Fig.6a, and the current scale clearly demonstrates the true theoretical SNR achieved within the rooms, therefore confirming the correctness of the simulations run. The highest SNR value of $5.33 \mathrm{~dB}$ dictates a BER of $5 \times 10^{-3}$ and $10^{-2}$ for successful binary phase-shift keying (BPSK) and quadrature PSK modulated transmissions, respectively.

\section{3. $5 G_{\text {room }}$}

One of the main conclusions from the comparison of the $4 \mathrm{G}$ and $5 \mathrm{G}$ simulations performed over the indoor hotspot scenario is, for an operational communication system working at higher frequency bands, a new indoor access network architecture concept has to be structured. It can be proposed that users who are within their offices need both higher throughput and peak data rates compared to the ones walking through the hall. The setting of the second $5 \mathrm{G}$ simulation stems from this idea, where BSs are placed at the centres of the ceiling of each room and $2 \mathrm{~cm}$ thick glass dividers replace the walls between the rooms and corridor. The outcomes are available in Fig.7. Received power within the rooms change from $0.0073 \mu \mathrm{W}$ to 0.0013 $\mu \mathrm{W}$, whereas the range for the corridor is $4.16 \times 10^{-15} \mathrm{~mW}$ to $5.38 \times 10^{-18} \mathrm{~mW}$. When the SNR results are examined from the Fig. $7 \mathrm{~b}$, it is seen that SNR values change from $5.31 \mathrm{~dB}$ to $-2.14 \mathrm{~dB}$ within the rooms, and $-87.14 \mathrm{~dB}$ to $-116.02 \mathrm{~dB}$ within the corridor. The outcome is still poor within the rooms, and the loss of $86.42 \mathrm{~dB}$ through $2 \mathrm{~cm}$ thick glass prevents any possibility of sustaining a communication link between the hall and BSs at $350 \mathrm{GHz}$. 


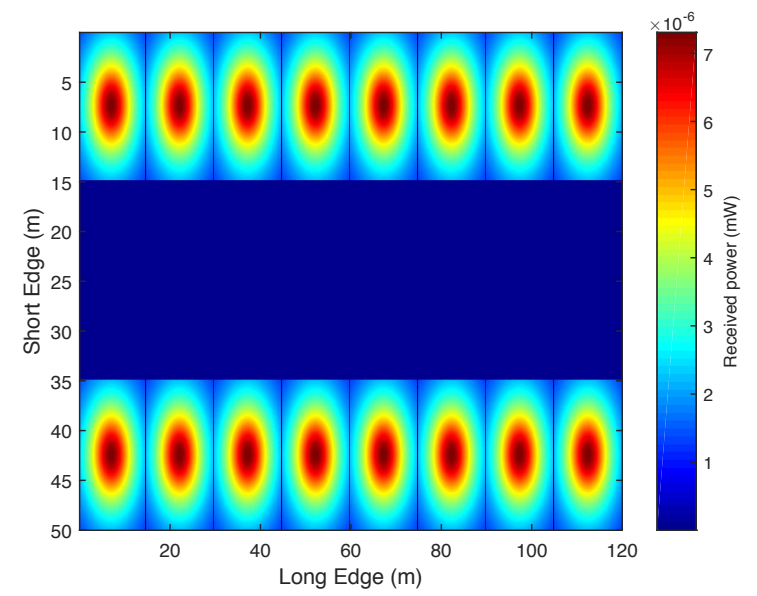

(a)

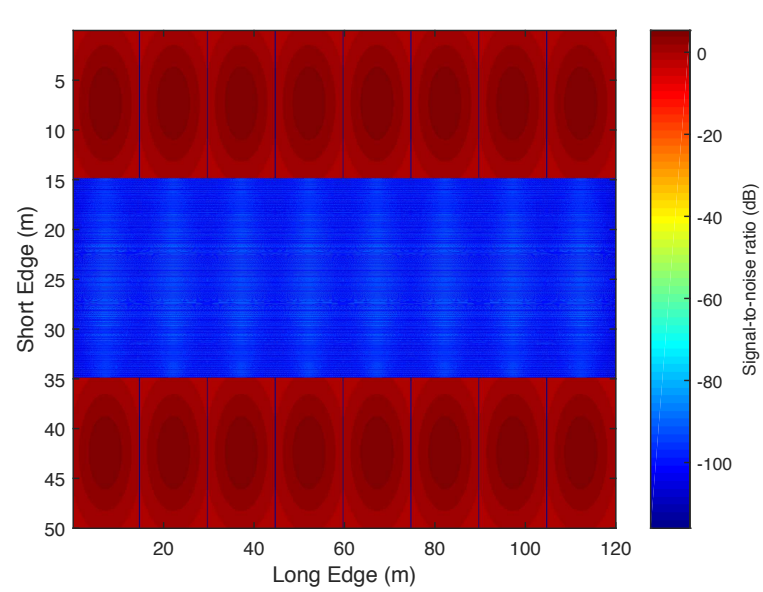

(b)

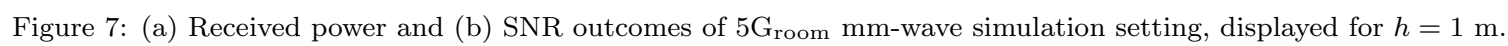

\section{4. $5 G_{\text {ideal }}$}

Third and final 5G simulation represents an ideal situation with hardware having lower NFs and SM, and BSs placed both in the rooms and the corridor without regard to cost, which normally is the key at general commercial deployments. The results are available in Fig.8. While received power ranges from $7.35 \times 10^{-6}$ $\mathrm{mW}$ to $1.84 \times 10^{-7} \mathrm{~mW}$ and $7.31 \times 10^{-6} \mathrm{~mW}$ to $1.31 \times 10^{-6} \mathrm{~mW}$ within the hall and rooms, respectively, SNRs for the same spaces change from $14.33 \mathrm{~dB}$ to $-1.67 \mathrm{~dB}$ and $14.31 \mathrm{~dB}$ to $6.85 \mathrm{~dB}$. Successful transmission with 16-QAM requires an SNR of $14.9 \mathrm{~dB}$ for $10^{-6} \mathrm{BER}$ and $5.2 \mathrm{~dB}$ is sufficient for BPSK transmission with $5 \times 10^{-3} \mathrm{BER}$. Therefore, the current setting is capable of supporting high data rate wireless communication at $350 \mathrm{GHz}$.

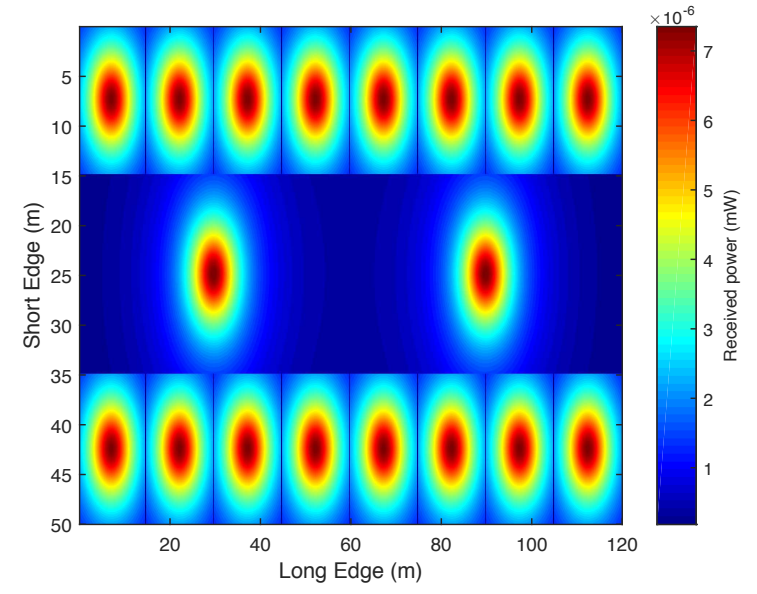

(a)

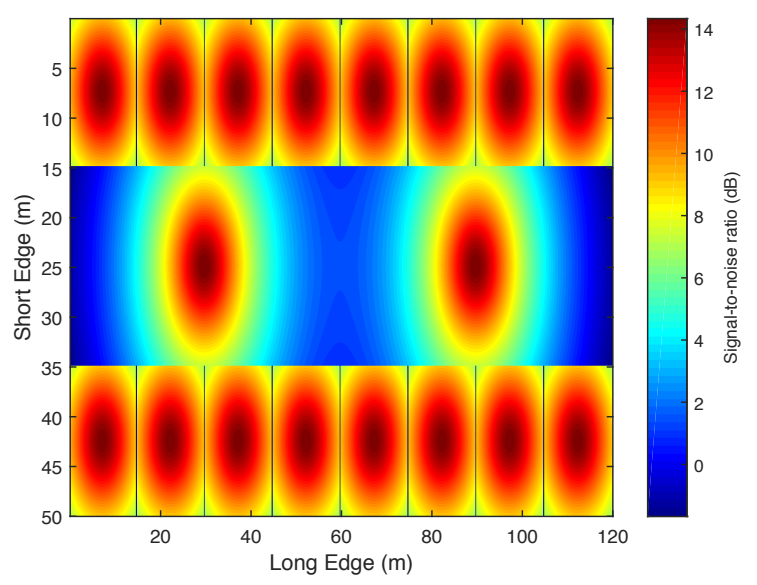

(b)

Figure 8: (a) Received power and (b) SNR outcomes of $5 \mathrm{G}_{\text {ideal }} \mathrm{mm}$-wave simulation setting, displayed for $h=1 \mathrm{~m}$. 


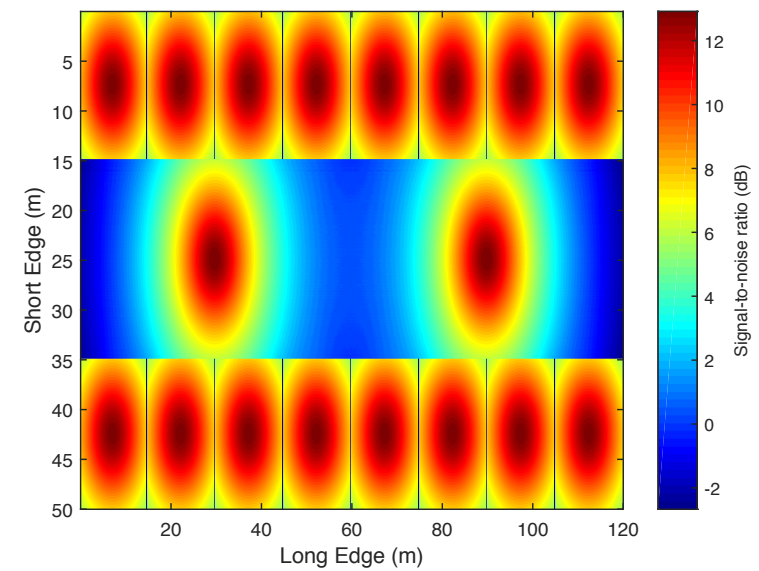

(a)

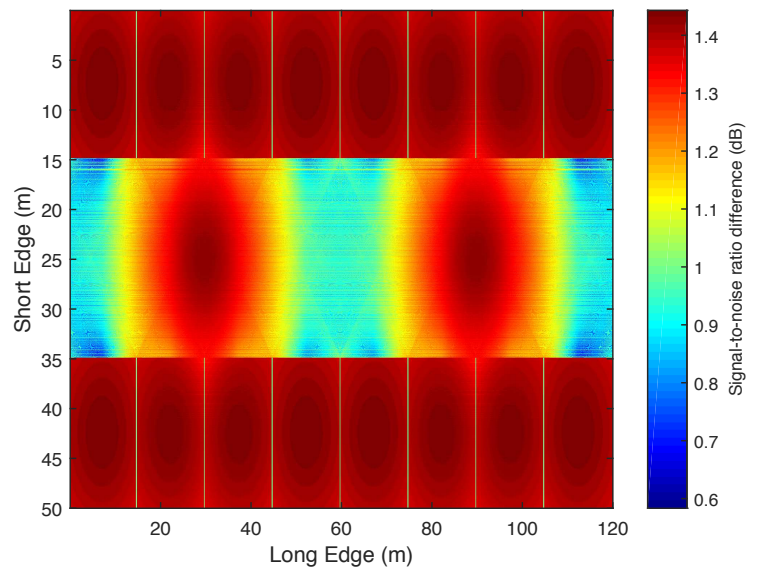

(b)

Figure 9: (a) SNR performance of $60 \mathrm{GHz}$ simulation and (b) SNR outcome difference between $5 \mathrm{G}_{\text {ideal }}$ and $60 \mathrm{GHz}$ simulations, displayed for $h=1 \mathrm{~m}$.

\section{5. $60 \mathrm{GHz}$}

Since the core focus of this work is low- $\mathrm{THz}$ band, received power outcome of the $60 \mathrm{GHz}$ simulation is omitted, whereas the SNR results are available in Fig.9a. The values change between $12.91 \mathrm{~dB}$ and $-2.67 \mathrm{~dB}$ within the hall, and from $12.87 \mathrm{~dB}$ to $5.49 \mathrm{~dB}$ in the rooms. This indicates a performance drop of $1.44 \mathrm{~dB}$ to $0.58 \mathrm{~dB}$ across the floor compared to the idealized 5G setting. Point-to-point SNR differences between the final two simulations are illustrated in Fig.9b.

Even though $60 \mathrm{GHz}$ simulation is resulted in lower SNR values, two important points need to be taken into consideration before any further analyses. Firstly, the total of NFs and SM, which has a direct effect on the consequent SNR, is $9 \mathrm{~dB}$ lower in the $5 \mathrm{G}_{\text {ideal }}$ case. Secondly, although the final $5 \mathrm{G}$ simulation is set using attainable targets, $60 \mathrm{GHz}$ parameters are selected from readily available hardware. Overall, while the $60 \mathrm{GHz}$ ISM band certainly performs better under evener conditions, low-THz band is not afar, and the additional benefits justify the research efforts.

\section{Conclusion}

The suitability of the low- $\mathrm{THz}$ band for $5 \mathrm{G}$ mobile communication systems is examined in this paper using both theoretical analyses and numerical simulations. Free-space path loss, atmospheric attenuation and absorption and reflection losses are all higher for the $\mathrm{THz}$ band compared to the sub $6 \mathrm{GHz}$ bands, limiting the coverage area of BSs. However, this can be offset by the network densification expected from the $5 \mathrm{G}$. Simulation results clearly show that it is possible to achieve peak data rates on the order of 10 $\mathrm{Gb} / \mathrm{s}$ using the low- $\mathrm{THz}$ band, though $\mathrm{THz}$ band signals are confined within the room containing the AP. There are still several important challenges that need to be solved during the standardization processes before actual deployments. High-performance and low-cost devices are needed to be able to implement the communication systems. Novel access network architecture solutions should be devised to overcome the greater losses in the $\mathrm{THz}$ band. A practical channel model is also compulsory for the continuation of the theoretical research efforts.

\section{Acknowledgement}

This work was supported in part by the Scientific and Technological Research Council of Turkey (TUBITAK) under grant \#113E962. 


\section{References}

[1] G. Fettweis, F. Guderian, S. Krone, Entering the path towards terabit/s wireless links, in: Design, Automation \& Test in Europe Conference \& Exhibition (DATE), 2011, pp. 1-6. doi:10.1109/DATE.2011.5763075.

[2] The World in 2014: ICT Facts and Figures, Report, International Telecommunication Union (2014).

[3] Cisco Visual Networking Index: Global Mobile Data Traffic Forecast Update, 2014-2019, Report, Cisco Systems, Inc. (2015).

[4] J. G. Andrews, S. Buzzi, C. Wan, S. V. Hanly, A. Lozano, A. C. K. Soong, J. C. Zhang, What Will 5G Be?, Selected Areas in Communications, IEEE Journal on 32 (6) (2014) 1065-1082. doi:10.1109/JSAC.2014.2328098.

[5] Standard ECMA-387: High Rate $60 \mathrm{GHz}$ PHY, MAC and HDMI PALs (2010) 1-302.

[6] IEEE Standard for Information technology - Telecommunications and information exchange between systems - Local and metropolitan area networks - Specific requirements. Part 15.3: Wireless Medium Access Control (MAC) and Physical Layer (PHY) Specifications for High Rate Wireless Personal Area Networks (WPANs) Amendment 2: Millimeter-wavebased Alternative Physical Layer Extension, IEEE Std 802.15.3c-2009 (Amendment to IEEE Std 802.15.3-2003) (2009) c1-187doi:10.1109/IEEESTD.2009.5284444.

[7] IEEE Standard for Information technology-Telecommunications and information exchange between systems-Local and metropolitan area networks-Specific requirements-Part 11: Wireless LAN Medium Access Control (MAC) and Physical Layer (PHY) Specifications Amendment 3: Enhancements for Very High Throughput in the $60 \mathrm{GHz}$ Band, IEEE Std 802.11ad-2012 (Amendment to IEEE Std 802.11-2012, as amended by IEEE Std 802.11ae-2012 and IEEE Std 802.11aa2012) (2012) 1-628doi:10.1109/IEEESTD.2012.6392842.

[8] The radio regulations, edition of 2012 (2012). URL http://www.itu.int/pub/R-REG-RR-2012

[9] G. R. MacCartney, T. S. Rappaport, $73 \mathrm{GHz}$ millimeter wave propagation measurements for outdoor urban mobile and backhaul communications in New York City, in: Communications (ICC), 2014 IEEE International Conference on, pp. 4862-4867. doi:10.1109/ICC.2014.6884090.

[10] A. Maltsev, V. Erceg, E. Perahia, Channel models for $60 \mathrm{GHz}$ WLAN systems, IEEE 802.11-09/0334r8.

[11] Report ITU-R M.2135-1: Guidelines for evaluation of radio interface technologies for IMT-Advanced, ITU-R Recommendations and Reports, ITU, Geneva, Switzerland.

[12] Recommendation ITU-R P.835-5: Reference standard atmospheres, ITU-R Recommendations, P Series Fasicle, ITU, Geneva, Switzerland.

[13] Recommendation ITU-R P.676-9: Attenuation by atmospheric gases, ITU-R Recommendations, P Series Fasicle, ITU, Geneva, Switzerland.

[14] Recommendation ITU-R P.838-3: Specific attenuation model for rain for use in prediction methods, ITU-R Recommendations, P Series Fasicle, ITU, Geneva, Switzerland.

[15] T. Yilmaz, O. B. Akan, Utilizing terahertz band for local and personal area wireless communication systems, in: Computer Aided Modeling and Design of Communication Links and Networks (CAMAD), 2014 IEEE 19th International Workshop on, pp. 330-334. doi:10.1109/CAMAD.2014.7033260.

[16] T. Yilmaz, O. B. Akan, Wireless Networks Evolution: Communications at $60 \mathrm{GHz}, \mathrm{CRC}$ Press, 2016, p. PP.

[17] H. T. Friis, A note on a simple transmission formula, Proc. IRE 34 (5) (1946) 254-256.

[18] R. Piesiewicz, C. Jansen, S. Wietzke, D. Mittleman, M. Koch, T. Kurner, Properties of Building and Plastic Materials in the $\mathrm{THz}$ Range, International Journal of Infrared and Millimeter Waves 28 (5) (2007) 363-371. doi:10.1007/s10762-0079217-9.

[19] T. S. Rappaport, S. Shu, R. Mayzus, Z. Hang, Y. Azar, K. Wang, G. N. Wong, J. K. Schulz, M. Samimi, F. Gutierrez, Millimeter Wave Mobile Communications for 5G Cellular: It Will Work!, Access, IEEE 1 (2013) 335-349. doi:10.1109/ACCESS.2013.2260813.

[20] W. Roh, S. Ji-Yun, P. Jeongho, L. Byunghwan, L. Jaekon, K. Yungsoo, C. Jaeweon, C. Kyungwhoon, F. Aryanfar, Millimeter-wave beamforming as an enabling technology for $5 \mathrm{G}$ cellular communications: theoretical feasibility and prototype results, Communications Magazine, IEEE 52 (2) (2014) 106-113. doi:10.1109/MCOM.2014.6736750.

[21] B. Tianyang, A. Alkhateeb, R. Heath, Coverage and capacity of millimeter-wave cellular networks, Communications Magazine, IEEE 52 (9) (2014) 70-77. doi:10.1109/MCOM.2014.6894455.

[22] C. Jastrow, K. Munter, R. Piesiewicz, T. Kurner, M. Koch, T. Kleine-Ostmann, 300 ghz transmission system (2008).

[23] C. Jastrow, S. Priebe, B. Spitschan, J. Hartmann, M. Jacob, T. Kurner, T. Schrader, T. Kleine-Ostmann, Wireless digital data transmission at $300 \mathrm{GHz}$, Electronics Letters 46 (9) (2010) 661-663. doi:10.1049/el.2010.3509.

[24] T. J. Chung, W.-H. Lee, 10-Gbit/s Wireless Communication System at 300 GHz, ETRI Journal 35 (3) (2013) $386-396$. doi:http://dx.doi.org/10.4218/etrij.13.0112.0351.

[25] S. Priebe, T. Kurner, Stochastic Modeling of THz Indoor Radio Channels, Wireless Communications, IEEE Transactions on 12 (9) (2013) 4445-4455. doi:10.1109/TWC.2013.072313.121581.

[26] T. Yilmaz, E. Fadel, O. B. Akan, Employing $60 \mathrm{GHz}$ ISM band for $5 \mathrm{G}$ wireless communications, in: Communications and Networking (BlackSeaCom), 2014 IEEE International Black Sea Conference on, pp. 77-82. doi:10.1109/BlackSeaCom.2014.6849009.

[27] T. K. Sarkar, J. Zhong, K. Kyungjung, A. Medouri, M. Salazar-Palma, A survey of various propagation models for mobile communication, Antennas and Propagation Magazine, IEEE 45 (3) (2003) 51-82. doi:10.1109/MAP.2003.1232163.

[28] M. Jacob, S. Priebe, R. Dickhoff, T. Kleine-Ostmann, T. Schrader, T. Kurner, Diffraction in $\mathrm{mm}$ and Sub-mm Wave Indoor Propagation Channels, Microwave Theory and Techniques, IEEE Transactions on 60 (3) (2012) 833-844. doi:10.1109/TMTT.2011.2178859. 
[29] J. W. Lamb, Miscellaneous data on materials for millimetre and submillimetre optics, International Journal of Infrared and Millimeter Waves 17 (12) (1996) 1997-2034. doi:10.1007/BF02069487.

[30] C. A. Balanis, Advanced Engineering Electromagnetics, John Wiley and Sons, New York, 1989.

Turker Yilmaz received B.S. and MSc degrees in electrical and electronics engineering from Bogazici University and University College London in 2008 and 2009, respectively. He is currently a research assistant at the NWCL and pursuing his Ph.D. degree within the Department of Electrical and Electronics Engineering, Koc University, Istanbul, Turkey. His current research interests include terahertz and space communications.

Ozgur B. Akan is currently a full professor with the Department of Electrical and Electronics Engineering, Koc University and Director of the NWCL. His current research interests are in wireless communications, nanoscale and molecular communications, and information theory. He is an Associate Editor of IEEE Transactions on Communications, IEEE Transactions on Vehicular Technology, International Journal of Communication Systems (Wiley), Nano Communication Networks Journal (Elsevier), and European Transactions on Telecommunications. 